\title{
The Limits to Growth Revisited
}

\author{
by Ugo Bardi \\ Briefs in Energy, Energy Analysis, New York: Springer, 2011 \\ ISBN 978-1-4419-9416-8 \\ Softcover, $\$ 49.95,119$ pp.
}

\author{
Reviewed by Thomas K. Burch \\ Population Research Group/Department of Sociology \\ University of Victoria
}

Someone once described the British novelist E.M. Forster as "the wisest of men in the fewest of words." Reading this book reminded me of that comment. In just over 100 pages, an Italian chemist gives a lucid and balanced re-evaluation of the famous/notorious "Limits to Growth" project, first published in 1972 and revised as late as 2004. The study was sponsored by the Club of Rome with the aim of analysing the "world predicament," and suggesting policies that might deal with it. The central message was that our current world system was on inherently unsustainable paths, that endless exponential growth - in population, resource use, food production, consumption, pollution, etc. - was likely to lead to major breakdowns in the early to middle decades of the 21 st century. The authors' policy prescription was for unprecedented international co-operation in order to overhaul the system, a task that they recognized as extremely difficult. The book covers much of the same ground as Naomi Klein's recent bestseller, This Changes Everything: Capitalism vs. Climate Change, but more briefly and more narrowly, as a re-evaluation of one particular scientific study and analytic genre.

By Bardi's account, the study first received much positive acclaim, and then was trashed-notably by economists - and largely ignored. More recently there has been renewed interest and a more sympathetic hearing, as the study is seen to have continuing relevance to current environmental, demographic, economic, and political instabilities.

In twelve brief chapters, the University of Florence professor (1) explains the role of models in science and the character of "systems dynamics" models-essentially, systems of differential equations solved numerically by computer; (2) gives simple concrete examples of such a model, dealing with the British coal industry and the rise and fall of the whaling industry in the 19th century; (3) describes the World Model, the main tool of the Limits to Growth study; (4) details and evaluates scientific and political criticisms of the model; (5) considers mineral resources as possible limits to growth, and the potential role of technology in coping with such limits; and (6) describes a revival of world modelling, seen as a much-needed analytical tool for dealing with worldwide economic and environmental problems. 
A discussion of so much substance in 100 pages might suggest superficiality. But Bardi is nowhere superficial. Rather, he writes in tight scientific prose-but not so technical as to baffle the nonscientific reader-with frequent graphs and diagrams, and specific references to a large (10 pages) and varied bibliography.

Bardi shows that much of the criticism of "Limits to Growth" was based on a misunderstanding of the nature and purpose of systems dynamics models (some was based on cherry-picking of the data, some on outright mistaken readings of tables). The original authors were careful to note that their quantitative results for the future were not predictions, but simply the logical outcomes of their model and assumed inputs, what have come to be known as "scenarios." But, as Bardi makes clear, the results were "robust" - over a wide range of assumptions about such things as proven mineral reserves and technological progress, the qualitative result is always the same. The world system is heading for serious trouble; only the extent of that trouble and its timing are in doubt.

As before, some will dismiss Bardi as a "doomsayer." But as he points out, Cassandra's dire predictions in ancient Greece came true. A look at the state of the world today suggests one needn't look to the future for elements of doom; they're here already.

In chapter 9, on "Mineral Resources as Limits to Growth," there is a perceptive account of the definitional games some critics of the study played in order to suggest never-ending abundance of resources, culminating in economist Julian Simon's assertion that they were essentially infinite. Chapter 10 provides a similar discussion of the limits to technology as a solution to all our problems, questioning economist Solow's and computer scientist/futurologist Kurzweil's conviction that technology will continue to increase exponentially. Bardi notes, for example, that once a transistor consists of a single atom, a physical limit has been reached. He also reminds us that often as not, new technologies do have negative side effects. For example, the more energy we produce and use, the more thermal pollution (e.g., fossils fuels, $\mathrm{CO}_{2}$ and global warming): "Pollution is a necessary consequence of everything we do-including fighting pollution." Fracking has increased oil and gas production, but it also can cause earthquakes. In late August, the British Columbia government revealed that BC had experienced many fracking-related quakes, including two at 4.4 on the Richter scale, apparently a world record.

Even though the book is only four years old, many things have changed in the interim, so that in some ways it seems dated. He speaks of our being in a period of sustained high prices for oil, whereas the current price of conventional crude is less than $\$ 40$ oil as I write. Bardi didn't anticipate the rapid spread of "horizontal fracking," which has led to the US suddenly becoming one of the largest producers of oil in the world. Nor did he foresee that the Saudis would gear their production to maintain market share, rather than to keep prices high, or that slightly declining growth in the Chinese economy would affect prices on the demand side.

By the same token, many of our environmental problems are even worse than when he wrotedrought, ocean acidification, melting glaciers and polar ice, and rising sea levels, to name a few. And recent studies suggest that per capita agricultural production may have begun to decline, as was envisioned by the Limits to Growth models. The very fact that so much could change so quickly is a reminder that our world system is just that - a system, a complex dynamic system with many feedback loops and non-linear relationships. Not everyday thinking, nor even the linear multivariate models so beloved of empirical social scientists, can give us an adequate understanding of our world. 
Given the pace of change, a revised edition of this book would be welcome, to take account of recent developments and at the same time correct some small but annoying inconsistencies between the text references and the bibliography.

Bardi reminds us that the Limits to Growth study was conceived and implemented in the early 1970s, at a time when computers and analytic software were still relatively new. It would be surprising if one could not find flaws. Nevertheless, it pioneered a new way of thinking that is sorely needed in our study of current problems. Bardi correctly notes that all of us, including key decision makers, work with models about how the world works. But these are often poor models, typically static and linear, with vague and untested assumptions. Limits to Growth was open and specific about its assumptions, and the model was available for all to see, in contrast to those of many of its critics. It was, in short, a good scientific first step. It's our loss that it was not treated as such, especially by economists and demographers.

Page for page, Bardi's book is one of the most informative I have read in a long time. I would recommend it to anyone with an interest in our common future or in the methodology of science in general, and social science in particular. 